\title{
Are economists getting climate dynamics right and does it matter?
}

\author{
Simon Dietz ${ }^{1,2}$, Frederick van der Ploeg ${ }^{2,3,4}$, \\ Armon Rezai ${ }^{2,5}$ and Frank Venmans ${ }^{1,6}$
}

January 31, 2021

\begin{abstract}
We show that economic models of climate change produce climate dynamics inconsistent with current climate science models: (i) the delay between $\mathrm{CO}_{2}$ emissions and warming is much too long and (ii) positive carbon cycle feedbacks are mostly absent. These inconsistencies lead to biased economic policy advice. Controlling for how the economy is represented, different climate models result in significantly different optimal $\mathrm{CO}_{2}$ emissions. A long delay between emissions and warming leads to optimal carbon prices that are too low and attaches too much importance to the discount rate. Similarly we find that omitting positive carbon cycle feedbacks leads to optimal carbon prices that are too low. We conclude it is important for policy purposes to bring economic models in line with the state of the art in climate science and we make practical suggestions for how to do so.

Keywords: carbon cycle, carbon price, climate change, integrated assessment modelling, positive feedbacks, social cost of carbon

JEL codes: Q54

${ }^{1}$ London School of Economics and Political Science, London, UK

${ }^{2}$ CESifo, Munich, Germany

${ }^{3}$ University of Oxford, Oxford, UK

${ }^{4}$ University of Amsterdam, Amsterdam, The Netherlands

${ }^{5}$ Vienna University of Economics and Business, Vienna, Austria; IIASA, Laxenburg, Austria

${ }^{6}$ University of Mons, Mons, Belgium
\end{abstract}


Email for correspondence: s.dietz@lse.ac.uk. We would like to thank the editor and three anonymous referees, as well as David Anthoff, Henk Dijkstra, Carolyn Fischer, Gib Metcalf, Derek Lemoine, Reyer Gerlagh, Thomas Lontzek, Zack Miller, Felix Pretis, Glenn Rudebusch, James Stock and Richard Tol, for their comments and suggestions. We would also like to thank participants at AERE@ASSA 2021, AERE 2020, the Belgian Environmental Economics Day in Hasselt, the 2020 CESifo Area Conference on Energy \& Climate Economics, EAERE 2020, the European Geophysical Union 2020, the LSE-Imperial Workshop in Environmental Economics, SWEEEP, and the Virtual Seminar in Climate Economics, as well as seminar participants at Bologna, Cambridge, CIRED (Paris) and the European University Institute (Florence), for their input. We would like to acknowledge the financial support of the Grantham Foundation and FNRS. SD would also like to thank the Oxford Martin School at the University of Oxford, which hosted him for part of this research. The authors have no conflicts of interest or financial interests to disclose. 


\section{Introduction}

Climate change is arguably the quintessential dynamic problem in economics. Carbon dioxide resides in the atmosphere for centuries after it is emitted, while the climate system operates on timescales ranging from seconds to millennia. Presumably climate dynamics must be accurately represented in economic models of climate change, if appropriate policy prescriptions are to be made. But do economic models get climate dynamics right? To the extent that they don't, does it matter?

This paper aims to make two contributions. First, we highlight some key inconsistencies between how leading economic models of climate change represent climate dynamics and how the current generation of climate science models does. Second, we explore the economic implications of these inconsistencies. Using the economic module of Nobel laureate William Nordhaus' DICE model as a consistent representation of the economy, we quantify how different models of the climate system affect optimal $\mathrm{CO}_{2}$ prices/taxes, $\mathrm{CO}_{2}$ emissions and temperatures.

We conduct this study in response to some recent work hinting at a systemic problem. van Vuuren et al. (2011) have documented wide variations in the climate dynamics simulated by a sample of economic models, without analysing the economic implications. Calel and Stainforth (2017) and Rose et al. (2017) have come up with similar findings and also showed that these can result in variations in estimated economic impacts of climate change. In response to Lemoine and Rudik (2017), who argue that inertia in the climate system buys time for optimal $\mathrm{CO}_{2}$ prices to start low and grow slowly, Mattauch et al. (2020) argue that the Lemoine and Rudik (2017) model is out of line with the temperature impulse response to $\mathrm{CO}_{2}$ emissions in climate science models, and that bringing it into line significantly alters the optimal $\mathrm{CO}_{2}$ price path. ${ }^{1}$

We build on these studies in two main ways. First, we attempt a comprehensive assessment of climate dynamics in a representative sample of six leading economic models of climate change, a.k.a. integrated assessment models or IAMs, and we compare them with a canonical set of climate science models. We include not only quantitative/numerical IAMs like DICE, but also analytical IAMs built to yield closed-form solutions for optimal $\mathrm{CO}_{2}$ prices. Second, we demonstrate the implications of different climate dynamics for economic policy by computing optimal paths, using the economic module of DICE to control for all other relevant differences.

In Section 2, we elaborate on how the leading IAMs fail to conform to climate science

\footnotetext{
${ }^{1}$ Dietz and Venmans (2019) note a similar discrepancy between DICE 2013 and climate science models, without exploring the direct implications for $\mathrm{CO}_{2}$ prices.
} 
models. We select six models, which we argue are representative of the climate economics field: the three most influential quantitative IAMs (DICE, FUND and PAGE), together with three analytical IAMs from prominent recent papers (Golosov et al., 2014; Lemoine and Rudik, 2017; Gerlagh and Liski, 2018). We test how their climate modules respond in two experiments, compared with a large sample of 256 counterpart climate science models. The first test is of how fast and how far temperature rises in response to a $\mathrm{CO}_{2}$ emission impulse. We show that the climate science models uniformly heat up very quickly to a constant, steady-state level, whereas the climate modules of the IAMs heat up much more slowly and do not attain a steady-state temperature within two centuries. The second test is of how removal of atmospheric $\mathrm{CO}_{2}$ by carbon sinks (i.e. the oceans and biosphere) changes as $\mathrm{CO}_{2}$ emissions continue. In the climate science models, carbon sinks weaken. Their ability to remove $\mathrm{CO}_{2}$ from the atmosphere is diminished by positive feedbacks in the carbon cycle, leading to more warming from given emissions. By contrast, we show that $\mathrm{CO}_{2}$ removal by carbon sinks strengthens in most of the IAMs, giving a false impression of increasing absorptive capacity.

Section 3 offers a general framework to understand the models of the carbon cycle and warming process featured in these two experiments, both from climate science and economics. This framework enables us to decompose the dynamic temperature response to a $\mathrm{CO}_{2}$ emission impulse in the models into the dynamic response of (i) the atmospheric $\mathrm{CO}_{2}$ concentration and (ii) temperature. This decomposition demonstrates that the IAMs' climate modules vary widely in how fast a $\mathrm{CO}_{2}$ emission impulse decays and how much is removed from the atmosphere in the long run, and that the decay behaviour generally differs from the representative climate science model. In particular, most of the IAMs remove $\mathrm{CO}_{2}$ from the atmosphere too slowly at first, which would in fact result in a fast temperature response to a $\mathrm{CO}_{2}$ emission impulse, all else being equal. The second part of the decomposition shows, however, that almost all of the IAMs exhibit too much temperature inertia in response to elevated atmospheric $\mathrm{CO}_{2}$. Thus the very slow temperature response to emissions in the IAMs stems from too much temperature inertia.

In Section 4, we move on to exploring the economic implications of different representations of the climate system, i.e. we turn to whether any of this matters for climate policy. We couple various models of the climate system with a common economic module, namely that of DICE. This is sufficient to illustrate in controlled conditions that different climate models result in significantly different optimal $\mathrm{CO}_{2}$ emissions, concentrations and temperatures, both on emissions paths that maximise social welfare and on emissions paths that minimise $\mathrm{CO}_{2}$ abatement costs subject to a $2^{\circ} \mathrm{C}$ warming constraint (per the UN Paris Agreement on Climate Change). 
Since the various climate models differ in multiple ways, Section 5 isolates the effects of (i) too long a delay between emissions and warming and (ii) failing to simulate positive carbon cycle feedbacks. On the first, we find a long delay between an emission impulse and warming leads to optimal carbon prices that are too low. It also implies optimal carbon prices are too sensitive to the discount rate, since the costs of global warming are erroneously placed too far in the future. On the second, failing to simulate positive carbon cycle feedbacks also leads to optimal carbon prices that are too low. The effect is larger when cumulative $\mathrm{CO}_{2}$ uptake and temperature are high and overall it is of comparable size to a long delay. Lastly it is worth noting that we specifically find DICE 2016 heats up too much in the long run and this contributes to the false impression that it is infeasible to limit warming to $2^{\circ} \mathrm{C}$ as mandated by the UN Paris Agreement.

Section 6 concludes and offers a discussion. Climate dynamics matter. Some other issues in climate economics still matter at least as much, such as how to represent damages. But, unlike damages, the discrepancies between IAMs and current climate science models are easily fixed. We make recommendations on how to do so, depending on the complexity and purpose of those models.

\section{Two key tests of climate dynamics}

Our first test is of how global mean surface temperature responds to an emission impulse of 100 gigatonnes of carbon in the models. The background atmospheric $\mathrm{CO}_{2}$ concentration is held constant at 389 parts per million (the level observed in $2010^{2}$ ) and the equilibrium climate sensitivity is set to $3.1^{\circ} \mathrm{C}$. This replicates a well-known experiment in climate science (Ricke and Caldeira, 2014), which has also been recommended by the US National Academy of Sciences as a key test of the consistency of IAMs with current understanding in climate science (National Academies of Sciences, Engineering, and Medicine, 2017). Online Appendix A contains further details of the experiment.

To produce this figure, we first compute the temperature impulse response in 256 reducedform climate science models, which we obtained from the literature. ${ }^{3}$ The set of models here corresponds to the so-called CMIP5 ensemble, after the 5th Coupled Model Intercomparison Project of the World Climate Research Programme. We then combine these impulse

\footnotetext{
${ }^{2}$ https://data.giss.nasa.gov/modelforce/ghgases/Fig1A.ext.txt

${ }^{3}$ The set of 256 models is the product of all combinations of 16 carbon cycle models and 16 atmosphereocean general circulation models (AOGCMs). Many of the underlying models are highly complex and run on super-computers. However, previous research in climate science, which we build on here, shows that the dynamics they simulate for atmospheric $\mathrm{CO}_{2}$ and global mean surface temperature can be fit with a high degree of precision using reduced-form models (Geoffroy et al., 2013; Joos et al., 2013; Ricke and Caldeira, 2014), which enables comparisons like this one.
} 
responses with those of six leading IAMs, including the three most influential quantitative IAMs by far - DICE, FUND and PAGE ${ }^{4}$ - and three leading analytical IAMs published in recent years (Golosov et al., 2014; Gerlagh and Liski, 2018; Lemoine and Rudik, 2017). While this sample of economic models is not exhaustive, we argue it is representative of the field as a whole. ${ }^{5}$

Perhaps contrary to popular belief, the temperature response to a $\mathrm{CO}_{2}$ emission impulse in climate science models is fast. Figure 1 shows this. Peaking around ten years after the emission impulse, temperature is then permanently elevated. The response of the models resembles a step function. Dietz and Venmans (2019) explain the underlying geophysics. In comparison, Figure 1 also shows there is far too much delay between the injection of $\mathrm{CO}_{2}$ and the resulting peak warming in almost all the leading IAMs. The temperature response peaks after 55 years in DICE 2013, 67 years in PAGE and 75 years in the model of Gerlagh and Liski (GL18). In the central case studied by Lemoine and Rudik (LR17) it takes 92 years, in FUND it takes 128 years and in DICE 2016 it takes 180 years. The only model that does not simulate a long delay is that of Golosov et al. (GHKT14), which assumes no delay in the temperature response a priori. This turns out to be a reasonable approximation. After peaking, temperature begins to decrease again in the IAMs, which is also contrary to the climate science models.

This experiment involves a fairly large instantaneous emission impulse of $100 \mathrm{GtC}$, which is equivalent to about ten years of $\mathrm{CO}_{2}$ emissions from burning fossil fuels at current rates (Le Quéré et al., 2018). One may wonder whether the conclusions we draw are robust to the size of the emission impulse. Online Appendix A shows that they are. Qualitatively very similar results are obtained from a much smaller emission impulse (1GtC) and a much larger one $(1000 \mathrm{GtC})$. One may also wonder whether the rapid temperature impulse response is consistent with observational data, not just a property of the climate science models (noting these models are themselves calibrated on observations). Montamat and Stock (2020) provide evidence that this is the case, regressing temperature on atmospheric $\mathrm{CO}_{2}$ using an instrumental variables approach. Lastly, online Appendix A also shows that the temperature

\footnotetext{
${ }^{4}$ We include both DICE 2013 (Nordhaus, 2014) and DICE 2016 (Nordhaus, 2017), due to their divergent behaviour, FUND 3.11 (FUND 3.10 is described in Waldhoff et al., 2014) and PAGE09 (Hope, 2013).

${ }^{5}$ As an example of their policy application, DICE, FUND and PAGE are used in the United States to estimate the social cost of carbon - the marginal damage cost of $\mathrm{CO}_{2}$ - for the purposes of cost-benefit analysis of federal regulations (Interagency Working Group on Social Cost of Carbon, 2013). Of the analytical IAMs, the model of Golosov et al. has been particularly widely adopted in subsequent work, with 749 citations according to Google Scholar as of 13 January 2021. Few quantitative or analytical IAMs beyond these have been built to conduct cost-benefit analysis, i.e. to compute welfare-maximising emissions paths under endogenous climate damages/impacts from rising temperatures. The term IAM is sometimes applied to a much wider set of models, including energy models built to assess the costs of meeting pre-defined $\mathrm{CO}_{2}$ emissions budgets or targets. These models do not have climate modules, however.
} 
Figure 1: Dynamic temperature response of 256 climate science models (the CMIP5 ensemble) and seven IAMs to an instantaneous 100GtC emission impulse against a constant background atmospheric $\mathrm{CO}_{2}$ concentration of $389 \mathrm{ppm}$. The temperature response of the IAMs is much slower than the climate science models, except Golosov et al. (2014). After 200 years, the temperature response of the IAMs is often well outside the range of the climate science models. The CMIP5 model responses are emulated/fitted by combining the Joos et al. (2013) carbon cycle model and the Geoffroy et al. (2013) warming model.

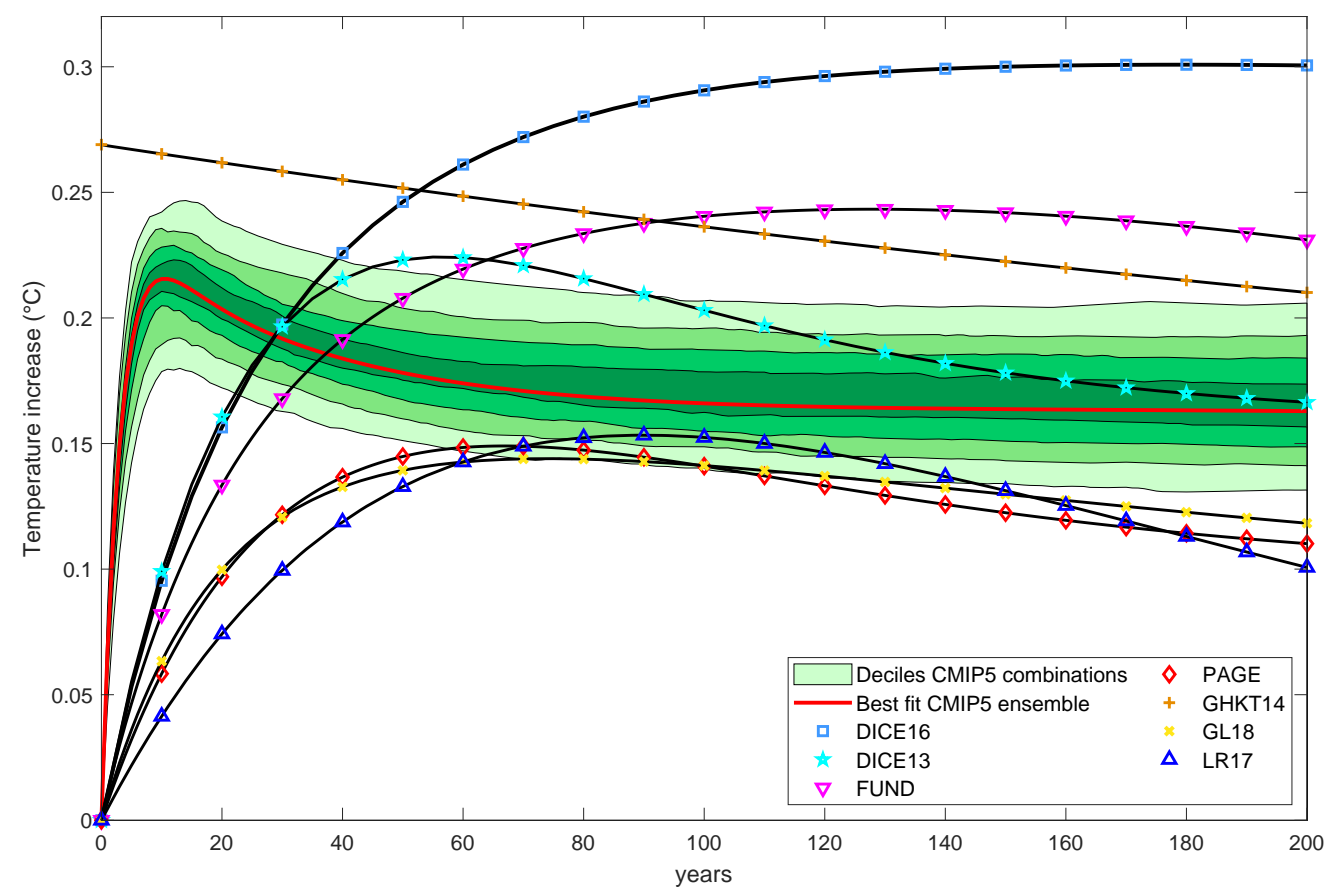


impulse responses of the models featured in our experiment are qualitatively very similar when background atmospheric $\mathrm{CO}_{2}$ is rising, rather than being held constant.

In Figure 2, we present the results of our second test. We run the models under a scenario of constant greenhouse gas emissions ${ }^{6}$ and plot how yearly uptake of $\mathrm{CO}_{2}$ by carbon sinks changes as the stock of atmospheric $\mathrm{CO}_{2}$ increases. Again, a comparison like this was identified by the National Academy of Sciences as a key test of IAMs (National Academies of Sciences, Engineering, and Medicine, 2017). The representative climate science model in this experiment is called FAIR (Millar et al., 2017). FAIR is based on the same reducedform model used to approximate the climate science models in Figure 1, but adds additional carbon cycle feedbacks. We calibrate FAIR on the mean climate science model depicted in Figure 1, and add carbon cycle feedbacks calibrated on observational data since pre-industrial by Millar et al. (2017). Online Appendix A contains further details of this experiment.

In FAIR, yearly uptake of $\mathrm{CO}_{2}$ by carbon sinks decreases as the atmospheric $\mathrm{CO}_{2}$ concentration increases. Carbon sinks become less effective at removing $\mathrm{CO}_{2}$ from the atmosphere, because of positive feedbacks in the carbon cycle. In the absence of these feedbacks, yearly uptake of $\mathrm{CO}_{2}$ by carbon sinks would increase with the atmospheric $\mathrm{CO}_{2}$ concentration, simply due to Henry's Law. ${ }^{7}$ Instead, as atmospheric $\mathrm{CO}_{2}$ rises, the oceans, like the atmosphere, warm up. As they do so, they keep less $\mathrm{CO}_{2}$ in solution, so more $\mathrm{CO}_{2}$ stays in the atmosphere, further increasing temperature. $\mathrm{CO}_{2}$ reacts with seawater to form carbonic acid, so the more $\mathrm{CO}_{2}$ the oceans absorb cumulatively, the more acidic they become, which also limits their ability to absorb carbon (Revelle and Suess, 1957). Furthermore, climate change is expected to reduce net uptake of $\mathrm{CO}_{2}$ by the biosphere. Most of the IAMs do not take these feedbacks into account, however. This explains why in these models there is an increasing relationship between atmospheric $\mathrm{CO}_{2}$ and annual $\mathrm{CO}_{2}$ removal by carbon sinks. The exceptions are FUND and PAGE, both of which incorporate feedbacks from carbon sinks to atmospheric $\mathrm{CO}_{2}$ /warming. In FUND but not in PAGE, these feedbacks are sufficient to produce a decreasing overall relationship between atmospheric $\mathrm{CO}_{2}$ and $\mathrm{CO}_{2}$ removal by sinks. ${ }^{8}$

\footnotetext{
${ }^{6}$ Fixed at the 2015 level. Doing so enables us to clearly show the effect of carbon cycle feedbacks, which would not be clear on an increasing emissions path, for reasons set out just below.

${ }^{7}$ The amount of dissolved gas in a liquid (i.e. the oceans) is proportional to its partial pressure above the liquid (i.e. in the atmosphere).

${ }^{8}$ There are multiple feedbacks in the carbon cycle, positive and negative. Changes to the ocean circulation could also reduce $\mathrm{CO}_{2}$ uptake (Friedlingstein et al., 2006). Potential sources of negative feedback include increased rainfall over currently arid areas. Overall, IPCC concluded that "[b]ased on Earth System Models, there is high confidence that the feedback between climate and the carbon cycle is positive in the 21st century" (IPCC, 2013, p26, original emphasis). In the unlikely event of an overall negative feedback, the slope of the relationship between annual $\mathrm{CO}_{2}$ uptake and atmospheric $\mathrm{CO}_{2}$ would be more positive. Not included here are further positive greenhouse gas feedbacks such as permafrost thawing, which tend instead
} 
Figure 2: Yearly uptake of $\mathrm{CO}_{2}$ by carbon sinks as a function of atmospheric $\mathrm{CO}_{2}$ in FAIR and seven IAMs under constant 2015 greenhouse gas emissions. Each marker represents five years. FAIR shows yearly uptake decreases, while the IAMs have it increasing, except FUND.

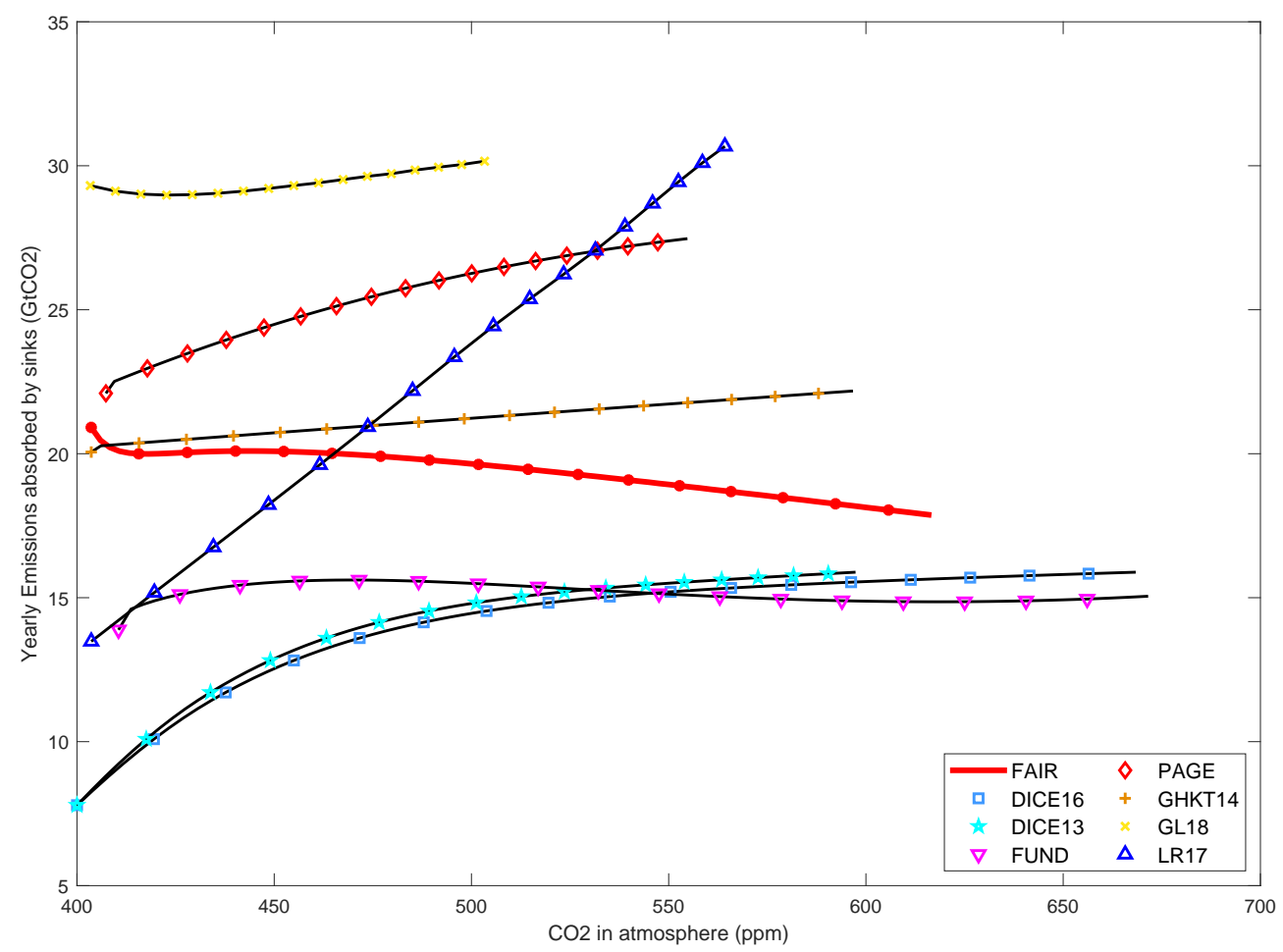


There is reason to believe these two discrepancies between the current crop of climate science models and the leading IAMs could matter for policy prescriptions. First, given the centrality of discounting in climate economics (Arrow et al., 2013; Gollier, 2012; Nordhaus, 2007; Stern, 2007), the fact that IAMs underestimate warming in the near future in response to a $\mathrm{CO}_{2}$ emission impulse could significantly impact the welfare evaluation of emissions abatement responses. According to the climate science models, $\mathrm{CO}_{2}$ emissions elevate temperatures almost immediately. Avoiding those emissions would therefore pay an almost immediate dividend. Second, ignoring the diminishing marginal effectiveness of carbon sinks underestimates the climate response to $\mathrm{CO}_{2}$ emissions in the long run, which again impacts the welfare evaluation of emissions abatement responses.

\section{Models of the carbon cycle and temperature dynam- ics}

How do the models used in the previous section - both the climate science models and the IAMs - actually work? In this section, we offer a general framework for understanding this using impulse response functions (see e.g. Maier-Reimer and Hasselmann, 1987). The framework enables us to decompose the temperature response to a $\mathrm{CO}_{2}$ emission impulse in the models into the response of (i) the atmospheric $\mathrm{CO}_{2}$ concentration and (ii) temperature. By describing the models in more detail, we also set the scene for our subsequent economic analysis, which is based on coupling different climate models with the DICE economic module.

Start by writing the temperature impulse response to an initial $\mathrm{CO}_{2}$ emission as plotted in Figure 1 as:

$$
\frac{\Delta T_{t}}{\Delta E_{1}}=\sum_{s=1}^{t} \frac{\Delta T_{t}}{\Delta F_{s}} \frac{\Delta F_{s}}{\Delta M_{s}} \frac{\Delta M_{s}}{\Delta E_{1}},
$$

where $T_{t}$ is the increase in global mean temperature at time $t$ relative to pre-industrial, $E$ is $\mathrm{CO}_{2}$ emissions, $F$ is radiative forcing and $M$ is the atmospheric $\mathrm{CO}_{2}$ concentration.

The temperature impulse response at time $t$ to a $\mathrm{CO}_{2}$ emission at time $t=1$ is thus the sum over the intervening period of the product of the $\mathrm{CO}_{2}$ concentration impulse response to the emission, $\Delta M_{s} / \Delta E_{1}$, the within-period change in forcing in response to atmospheric $\mathrm{CO}_{2}, \Delta F_{s} / \Delta M_{s}$, and lastly the change in temperature in response to the additional forcing, $\Delta T_{t} / \Delta F_{s}$. The $\mathrm{CO}_{2}$ concentration impulse response to the emission is determined by a carbon cycle model, while the forcing and temperature response to changing atmospheric $\mathrm{CO}_{2}$ is determined by a warming model. Let us now scrutinise these two models in turn.

to be classed as tipping points in the climate system (Lenton et al., 2008). 


\section{The carbon cycle model}

Most simple models of the carbon cycle partition the system into a series of reservoirs or boxes, between which carbon is exchanged. The diffusion of carbon between different boxes (e.g. the atmosphere, biosphere, and upper and lower oceans) can be modelled by a system of difference equations of the form

$$
\mathbf{m}_{t}=\mathbf{A} \mathbf{m}_{t-1}+\mathbf{b} E_{t}
$$

where the vector $\mathbf{m}_{t}$ contains the stocks of carbon in each of $n$ boxes at the end of period $t$ and $\mathbf{A}$ is a matrix, whose elements describe the speed of diffusion between the boxes. The vector $\mathbf{b}$ contains the shares of emissions that enter each of the boxes. As the matrix $\mathbf{A}$ and the vector $\mathbf{b}$ are constant, (2) corresponds to a linear carbon cycle.

The atmospheric $\mathrm{CO}_{2}$ concentration $M_{t} \equiv \mathbf{d}^{\prime} \mathbf{m}_{t}$, where $\mathbf{d}$ is the vector that maps the contents of the various boxes into the stock of atmospheric carbon. Then

$$
M_{t}=\mathbf{d}^{\prime}\left(\mathbf{A}^{t} M_{0}+\sum_{s=1}^{t} \mathbf{A}^{t-s} \mathbf{b} E_{s}\right)
$$

where $M_{0}$ is the initial concentration. In online Appendix B, we show how spectral decomposition can be used to obtain the $\mathrm{CO}_{2}$ concentration impulse response function:

$$
\frac{\Delta M_{t}}{\Delta E_{s}}=\mathbf{d}^{\prime} \mathbf{A}^{t-s} \mathbf{b}=\sum_{s=1}^{t} \sum_{i=1}^{n} \psi_{i} \lambda_{i}^{t-s}
$$

The $\lambda_{i} \in(0,1]$ are the eigenvalues of $\mathbf{A}$, which we assume to be real and in decreasing order of magnitude. These are inversely proportional to how long $\mathrm{CO}_{2}$ resides in each of the boxes. The constants $\psi_{i}>0$ represent the contribution of each box to the atmospheric carbon stock. If a proportion of emissions stays in the atmosphere forever, $\lambda_{1}=1$ for the box pertaining to that proportion $(i=1)$ and the impulse response is the sum of the permanent and transitory components,

$$
\frac{\Delta M_{t}}{\Delta E_{s}}=\psi_{1}+\sum_{i=2}^{n} \psi_{i} \lambda_{i}^{t-s} .
$$

Equation (5) fully determines any linear carbon cycle model with any number of boxes, which explains why such impulse response functions are commonly used in climate science to represent and compare models of varying degrees of complexity.

Table 1 applies this framework to the carbon cycle models compared in the previous section. Joos et al. (2013) is the representative climate science model, i.e. the model used to fit the CMIP5 ensemble. While the number of boxes varies, most models are based on a 
structure in which there is a permanent box, into which roughly $1 / 5$ to $1 / 6$ of a $\mathrm{CO}_{2}$ emission impulse flows, a very slowly decaying box, and one or more boxes that decay much more quickly. However, there is significant variation in both the shares of emissions flowing into each box and the residence time (specifically the half-life) of $\mathrm{CO}_{2}$ in each of the temporary boxes. ${ }^{9}$ Online Appendix B contains further details of the models' carbon cycles.

What $\mathrm{CO}_{2}$ dynamics do these different representations give rise to? Figure 3 plots the $\mathrm{CO}_{2}$ impulse responses of the various models. The impulse size is $100 \mathrm{GtC}$ as in the experiments above. The figure shows that the differences between the models' structures and parameters cause significant differences in their $\mathrm{CO}_{2}$ impulse responses. Some models such as GL18 remove $\mathrm{CO}_{2}$ very quickly initially. Others such as PAGE remove it very slowly. Over the first 50 years, however, most IAMs remove $\mathrm{CO}_{2}$ more slowly than the best fit of the CMIP5 ensemble, which in itself would tend to produce a fast temperature impulse response. After a couple of centuries, some IAMs such as LR17 remove most of the $\mathrm{CO}_{2}$ emission impulse. Others such as DICE 2016 and FUND remove relatively little. By then, there does not appear to be a systematic bias between the IAMs and the best fit of CMIP5. Overall, few of the IAMs resemble the best fit of CMIP5, however.

So far we have not addressed weakening carbon sinks. It is clear these are not represented by linear models, since the $\mathrm{CO}_{2}$ impulse response in Equation (4) does not depend on cumulative absorbed carbon, or temperature. Simple non-linear models of carbon cycle feedbacks include NICCS (Hooss et al., 2001) and FAIR (Millar et al., 2017). FAIR, which is now widely used, simulates weakening carbon sinks by extending the four-box carbon cycle of Joos et al. (2013). Relegating the details to online Appendix A, in essence FAIR works by reducing the rate at which carbon is removed from the atmosphere using a scaling factor $\alpha$ (i.e. replace the $\lambda_{i}$ with $\lambda_{i} / \alpha$ ), which is increasing in cumulative carbon uptake and temperature. Figure 3 shows FAIR's positive carbon cycle feedbacks in action: less $\mathrm{CO}_{2}$ is removed from the atmosphere when the emission impulse is against a higher (year 2100) background concentration of $\mathrm{CO}_{2} \cdot{ }^{10}$

\section{Radiative forcing and temperature dynamics}

The relationship between atmospheric $\mathrm{CO}_{2}$ and forcing is logarithmic, since $\mathrm{CO}_{2}$ becomes less effective at absorbing outgoing radiation at higher concentrations. The change in forcing

\footnotetext{
${ }^{9}$ The shares flowing into the three boxes of the GL18 model do not add up to one, since only $94 \%$ of box 1 pertains to the atmosphere (the rest is assumed to be absorbed immediately by the upper ocean). The half-life of $\mathrm{CO}_{2}$ in box 2 of DICE 2016 is much larger than in earlier versions of DICE, or in the other models shown.

${ }^{10}$ Corresponding with the year 2100 on the IPCC's RCP4.5 scenario. RCP stands for Representative Concentration Pathway. IPCC developed four RCP scenarios for the Fifth Assessment Report (Moss et al., 2010).
} 


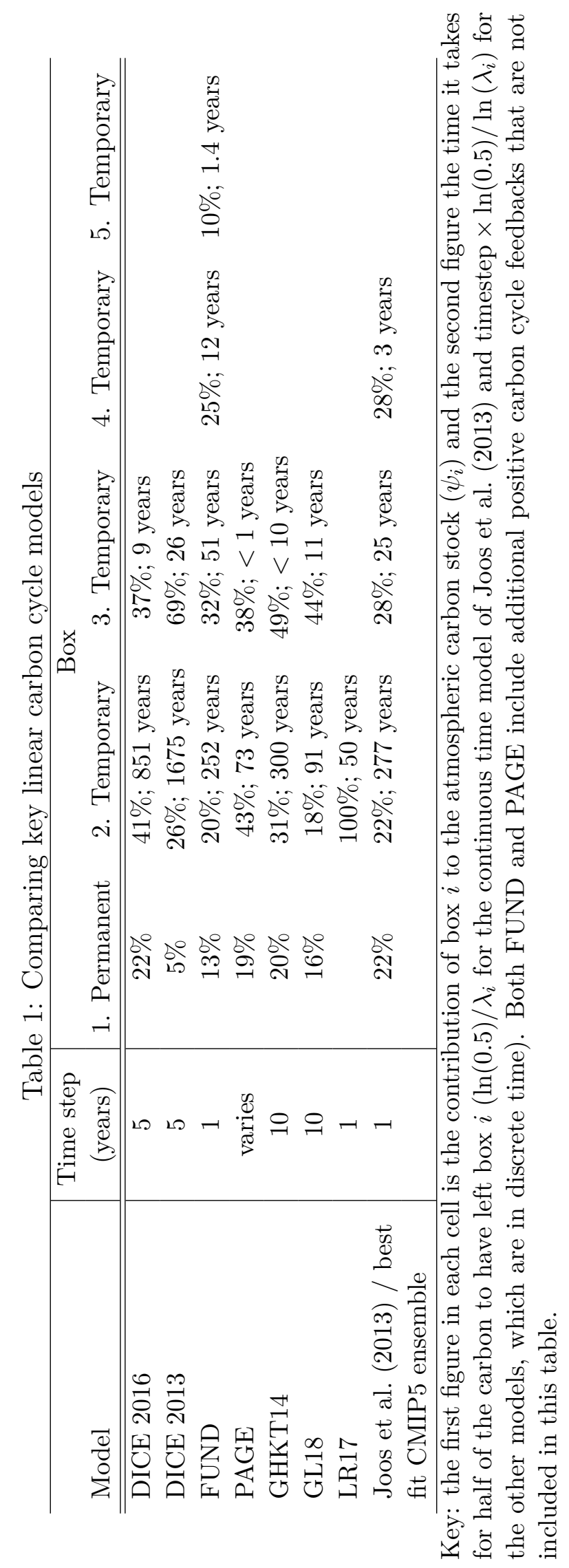


Figure 3: Removal of a 100GtC emission impulse $\left(47 \mathrm{ppm}^{\mathrm{CO}} \mathrm{CO}_{2}\right)$ in climate science models and seven IAMs against a constant background atmospheric $\mathrm{CO}_{2}$ concentration of 389ppm. There are big differences between the IAMs. Few of the IAMs approximate the best fit of the climate science model distribution. Note that FAIR removes less $\mathrm{CO}_{2}$ from the atmosphere against a higher background concentration due to positive carbon cycle feedbacks.

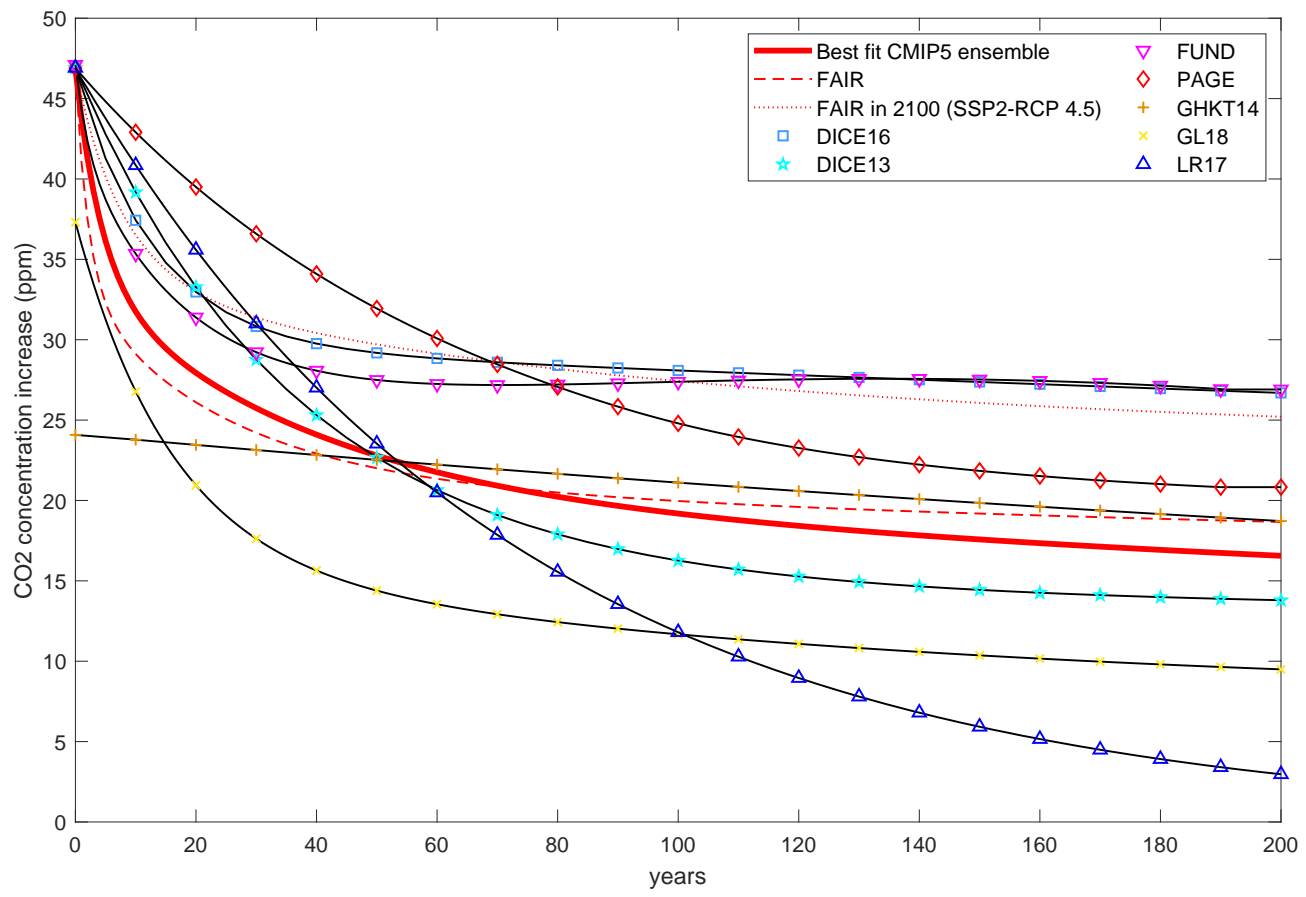


in response to atmospheric $\mathrm{CO}_{2}$ can be written as

$$
\frac{\Delta F_{s}}{\Delta M_{s}}=\frac{F_{2 \times C O_{2}}}{\ln 2} \frac{1}{M_{s}}
$$

where $\mathrm{F}_{2 \times \mathrm{CO}_{2}}$ is the radiative forcing resulting from doubling atmospheric $\mathrm{CO}_{2}$. This partly determines the equilibrium climate sensitivity, which we hold constant across all the models in order to isolate the effect of short- and medium-run dynamics (see online Appendix B). It is important to bear in mind that total radiative forcing is the sum of forcing from $\mathrm{CO}_{2}$ and from other greenhouse gases and forcing agents. Typically these other gases/forcing agents are exogenous in the models, ${ }^{11}$ but their role is not trivial ${ }^{12}$ and must be properly accounted for. Below we show that failing to do so in some models gives misleading results.

Just like carbon cycle models, simple warming models typically partition the system into boxes, between which heat is exchanged (e.g. the atmosphere/upper ocean and deep ocean). Thus we can again use spectral decomposition to obtain an analogous expression for the temperature response to forcing:

$$
\frac{\Delta T_{t}}{\Delta F_{s}}=\sum_{s=1}^{t} \sum_{i=1}^{2} \psi_{i}^{T} \lambda_{i}^{T-s}
$$

where $\psi_{i}^{T}$ and $\lambda_{i}^{T}$ denote respectively the shares/weights and eigenvalues of the heat boxes (the superscript $T$ just indicates that these apply to temperature).

Table 2 summarises the dynamics of the various warming models that map forcing into temperature. Geoffroy et al. (2013) is the representative climate science model used to fit the CMIP5 ensemble. Both DICE and Geoffroy et al. (2013) have two boxes representing the temperature of the atmosphere/upper oceans and the deep oceans respectively. However, critically DICE displays a much more sluggish response of temperature to radiative forcing than Geoffroy et al. (2013), especially as the fast box of Geoffroy et al. has a half-life of only 3 years.

Figure 4 uses Equations (6) and (7) to plot the dynamic temperature response of the models to a constant increase in atmospheric $\mathrm{CO}_{2}$ of $100 \mathrm{GtC}(47 \mathrm{ppm})$. This is therefore the second element of the decomposition of the temperature response to an emission impulse. With the exception of GHKT14, all of the IAMs exhibit a more sluggish temperature response than the best fit of the CMIP5 ensemble. The temperature response of LR17 is particularly slow. After 200 years, temperature is higher in DICE 2013, DICE 2016 and FUND, while

\footnotetext{
${ }^{11}$ In FUND and PAGE, some of the other greenhouse gases, such as methane and nitrous oxide, are explicitly modelled.

${ }^{12}$ The contribution to total radiative forcing of gases/drivers other than $\mathrm{CO}_{2}$ is about $25 \%$ currently (IPCC, 2013).
} 
Table 2: Comparing linear temperature-forcing responses

\begin{tabular}{l|c|c|c}
\hline & $\begin{array}{c}\text { Time step } \\
\text { (years) }\end{array}$ & Box 1 & Box 2 \\
\hline \hline DICE 2016 & 5 & $9.9 \% ; 25$ years & $0.2 \% ; 150$ years \\
DICE 2013 & 5 & $9.9 \% ; 23$ years & $0.2 \% ; 148$ years \\
FUND & 1 & $100 \% ; 31$ years & \\
PAGE & varies & $100 \% ; 24$ years & n.a. \\
GHKT14 & 10 & n.a. & \\
GL18 & 10 & $100 \% ; 34$ years & \\
LR17 & 1 & $100 \% ; 50$ years & \\
Geoffroy et al. (2013) / best & 1 & $13.5 \% ; 3$ years & $0.2 \% ; 167$ years \\
fit CMIP5 ensemble & & & \\
\hline
\end{tabular}

Key: The first figure in each cell is the weight of each mode and the second figure the half-life for each mode. PAGE models regional temperature and calculates global temperature as the areaweighted average. GHKT14 effectively assume that temperature is driven by equilibrium climate sensitivity according to Arrhenius' law and do not have any lag between forcing and temperature.

LR17 and PAGE are close to the best fit of the CMIP5 ensemble at that moment. The GHKT14 model shows an immediate, permanent increase in temperature. It over-predicts temperature compared with the best fit of the CMIP5 ensemble. 
Figure 4: Dynamic temperature response of the best-fit climate model and seven IAMs to a constant increase in atmospheric $\mathrm{CO}_{2}$ of $100 \mathrm{GtC}\left(47 \mathrm{ppm} \mathrm{CO}_{2}\right)$. The IAMs respond much more slowly to elevated $\mathrm{CO}_{2}$ than the best-fit climate model, except GHKT14.

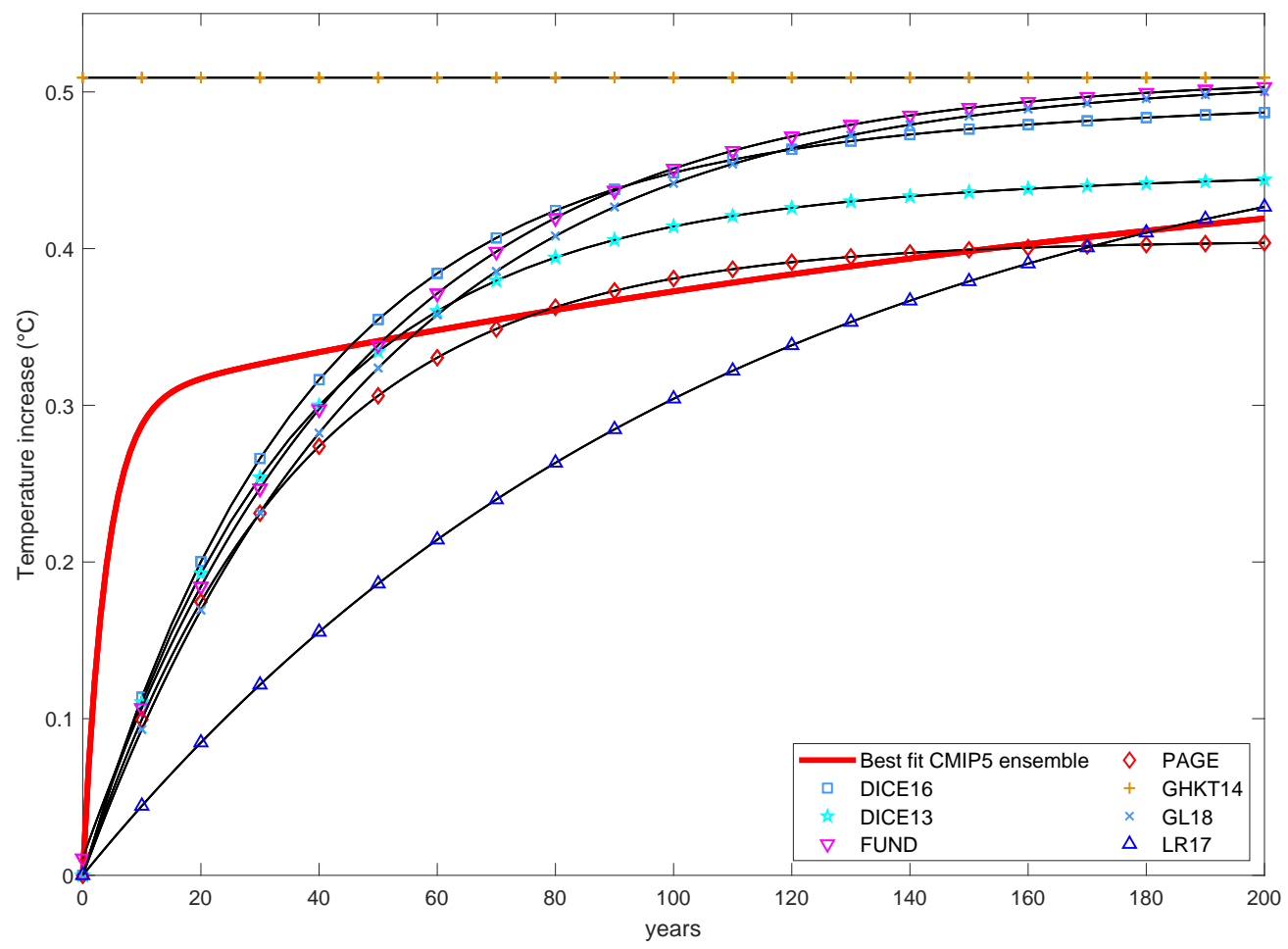

Going back to Figure 1, the IAMs (excluding GHKT14) warm up too slowly in response to the emission impulse. This impulse response is obtained by convoluting atmospheric $\mathrm{CO}_{2}$ decay/removal as plotted in Figure 3 with temperature inertia as plotted in Figure 4. Thus the analysis of this section shows that the sluggish temperature response to the emission impulse is due to too much temperature inertia in response to elevated atmospheric $\mathrm{CO}_{2}$. If anything, the IAMs have too little $\mathrm{CO}_{2}$ decay, but this does not compensate for the inertia. In the best fit of the CMIP 5 ensemble, temperature inertia almost exactly offsets $\mathrm{CO}_{2}$ decay. As a result, the CMIP5 temperature response resembles a step function.

\section{Economic policies with different climate models}

In this and the following section, we evaluate what difference the model of the climate system makes for economic policies. We focus on two such policies: (i) optimal emissions that maximise social welfare and (ii) a representative policy run in the context of the United 
Nations climate framework that limits warming to $2^{\circ} \mathrm{C}$ at minimum discounted abatement cost. The latter path is sometimes described as an exercise in cost-effectiveness analysis (as opposed to (i), which is an exercise in cost-benefit analysis) and is a core use of IAMs by IPCC (see Clarke et al., 2014). ${ }^{13}$

To perform this evaluation, we need to make a controlled comparison, in which the models are identical in all respects except how they represent the dynamics of the carbon cycle and warming process. Control is achieved by using the DICE 2016 economic and welfare modules as a common base, and coupling it with different models of the climate system (Table 3). ${ }^{14}$ We drop the FUND and PAGE models here, due to the practical difficulties of coupling these more complex IAMs with the DICE 2016 economy. Note that temperature is only implicit in GHKT14 and GL18, however it can be backed out using assumptions explicitly stated in these papers.

Table 3: List and description of models used for economic evaluation

\begin{tabular}{|c|c|}
\hline Model & Description \\
\hline DICE 2016 & Standard DICE 2016 economy and climate \\
\hline DICE-DICE 2013 & DICE 2016 economy with the DICE 2013 climate module \\
\hline DICE-GHKT14 & $\begin{array}{l}\text { DICE } 2016 \text { economy with the Golosov et al. (2014) } \\
\text { climate module }\end{array}$ \\
\hline DICE-GL18 & $\begin{array}{l}\text { DICE } 2016 \text { economy with the Gerlagh and Liski (2018) } \\
\text { climate module }\end{array}$ \\
\hline DICE-LR17 & $\begin{array}{l}\text { DICE } 2016 \text { economy with the Lemoine and Rudik (2017) } \\
\text { climate module }\end{array}$ \\
\hline DICE-FAIR-Geoffroy & $\begin{array}{l}\text { DICE } 2016 \text { economy with the FAIR carbon cycle and } \\
\text { the Geoffroy et al. (2013) warming model }\end{array}$ \\
\hline DICE-Joos-Geoffroy & $\begin{array}{l}\text { DICE } 2016 \text { economy with the Joos et al. (2013) carbon } \\
\text { cycle and the Geoffroy et al. (2013) warming model }\end{array}$ \\
\hline
\end{tabular}

Figure 5 plots welfare-maximising carbon prices, emissions and temperatures (left column) from DICE 2016, DICE-FAIR-Geoffroy (i.e. the representative or benchmark climate science model, coupled with the DICE economy), DICE-DICE 2013, DICE-GHKT14, DICEGL18 and DICE-LR17. It is immediately apparent that the models differ significantly in their welfare-maximising paths. Initial carbon prices range from $\$ 11 / \mathrm{tCO}_{2}$ in DICE-LR17 to $\$ 57$ in DICE-GHKT14, with an initial carbon price of $\$ 30$ in the benchmark DICE-FAIRGeoffroy model, and $\$ 37$ in standard DICE 2016. These differences grow over time, such

\footnotetext{
${ }^{13}$ Abatement cost minimisation subject to a temperature constraint is the same as welfare maximisation subject to a temperature constraint and ignoring climate damages.

${ }^{14}$ Readers are referred to William Nordhaus' web resources for a comprehensive description of the DICE 2016 economic module and, unless otherwise specified, the version we use is unchanged. See https://sites.google.com/site/williamdnordhaus/dice-rice.
} 
that by 2100 the range is $\$ 77-358 / \mathrm{tCO}_{2}$.

Welfare-maximising $\mathrm{CO}_{2}$ emissions and temperatures also vary widely. Initial $\mathrm{CO}_{2}$ emissions range from $33 \mathrm{GtCO}_{2}$ in DICE-GHKT14 to $40 \mathrm{GtCO}_{2}$ in DICE-LR17, while in 2100 they range from nearly zero to $50 \mathrm{GtCO}_{2}$. Optimal warming by the end of the century ranges from just $2.0^{\circ} \mathrm{C}$ in DICE-LR17 to $4.0^{\circ} \mathrm{C}$ in DICE-GHKT14. Optimal warming in the benchmark DICE-FAIR-Geoffroy model is $3.0^{\circ} \mathrm{C}$ in 2100 . Notice that optimal warming in 2100 is lowest in DICE-LR17, despite this model having the lowest carbon prices and the highest emissions. This is directly attributable to its slow and low temperature impulse response to $\mathrm{CO}_{2}$ emissions, as shown in Figure 1. Notice also the high initial starting temperature in DICE-GHKT14. Temperature is only implicit in GHKT14, but can be backed out from their assumptions about the atmospheric carbon stock and damages. Their assumption of no delay between emissions and warming, coupled with a calibration that ignored the contribution of non- $\mathrm{CO}_{2}$ greenhouse gases to warming, leads to this artefactual result.

Figure 5 also compares models on a path that limits warming to $2^{\circ} \mathrm{C}$ at minimum discounted abatement cost (right column). Similar to the models' welfare-maximising paths, we observe large differences in their $2^{\circ} \mathrm{C}$ cost-minimising paths. Naturally, given the warming constraint, the differences are particularly evident in carbon prices and emissions. Initial carbon prices vary from $\$ 13 / \mathrm{tCO}_{2}$ in DICE-LR17 to $\$ 143$ in standard DICE 2016. By midcentury the range of carbon prices peaks at $\$ 406 / \mathrm{tCO}_{2}$ between these models. Initial $\mathrm{CO}_{2}$ emissions range from $26 \mathrm{GtCO}_{2}$ in DICE 2016 to $40 \mathrm{GtCO}_{2}$ in DICE-LR17. Limiting warming to $2^{\circ} \mathrm{C}$ is infeasible in DICE-GHKT14, for the reasons mentioned above. In order to limit warming to $2^{\circ} \mathrm{C}$, emissions must eventually be negative in all models, but the time at which 'net zero' is crossed ranges from just before 2050 in DICE 2016 to just after 2100 in DICELR17. Although warming is limited to $2^{\circ} \mathrm{C}$, the temperature trajectory shows significant variation across the models, particularly in mid-century. The range is $1.2-1.8^{\circ} \mathrm{C}$ in 2050 , for instance. Note these $2^{\circ} \mathrm{C}$ cost-minimising paths are obtained assuming $\mathrm{CO}_{2}$ emissions from land-use change and forestry, as well as radiative forcing from other greenhouse gases and atmospheric agents, follow the IPCC RCP2.6 scenario, which is the only RCP scenario consistent with the $2^{\circ} \mathrm{C}$ target. We will return to this point below.

\section{Warming delay, positive carbon cycle feedbacks and further economic analysis}

While Figure 5 illustrates that climate dynamics matter for economic policies, it does not fully illuminate the role of the issues identified in Section 2, namely the excessive delay 
Figure 5: Welfare-maximising (left) and cost-minimising (right) paths from different climate models coupled with the DICE 2016 economy. Top row - carbon prices; middle row - $\mathrm{CO}_{2}$ emissions; bottom row - warming. The models produce very different carbon price paths, resulting in very different $\mathrm{CO}_{2}$ emissions and temperature paths.
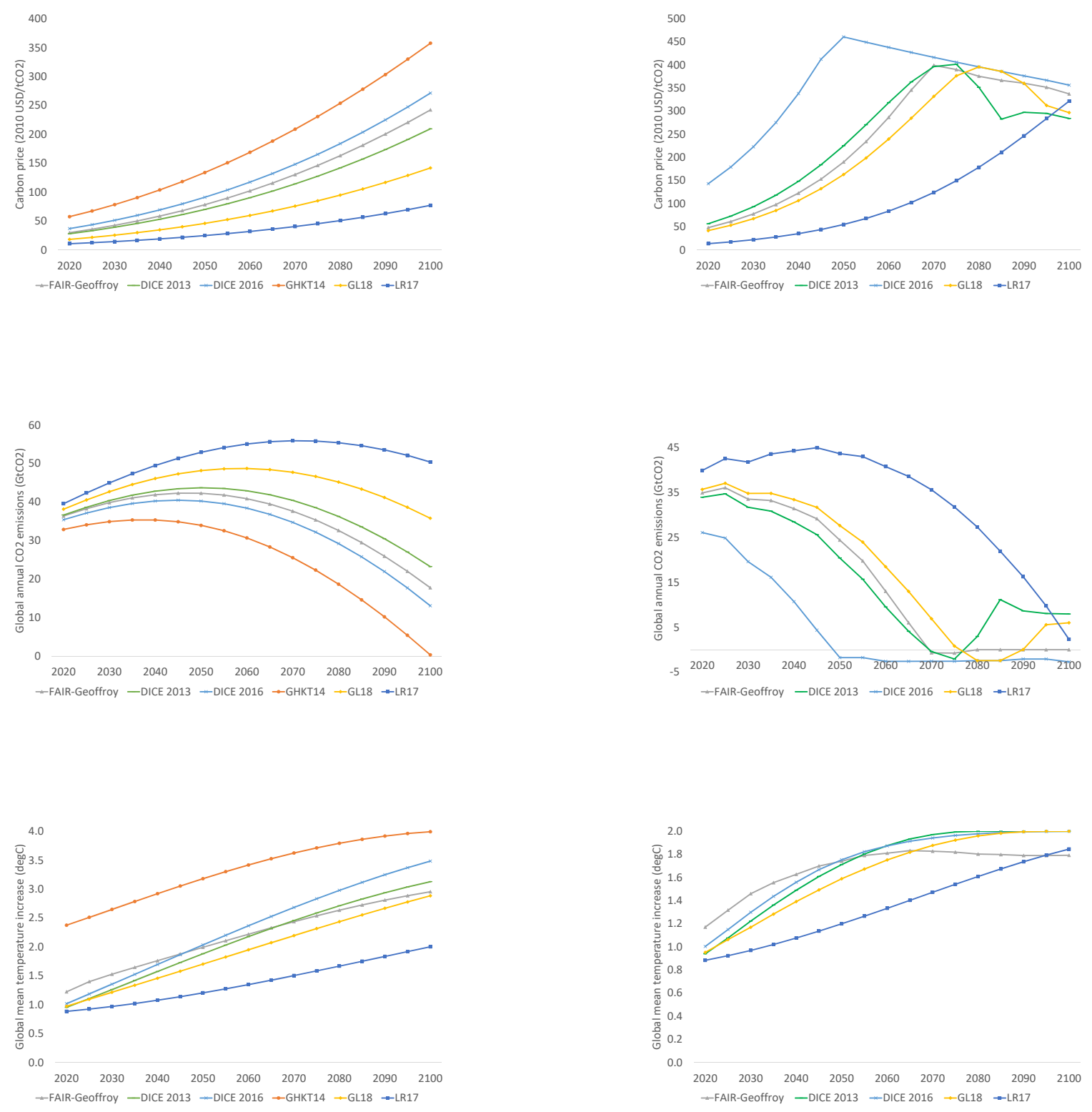

between a $\mathrm{CO}_{2}$ emission impulse and warming, and the omission of positive feedbacks in the carbon cycle. That is because the climate modules considered differ in multiple respects. Therefore these two issues are explored further in Tables 4 and 5 .

To isolate the effect of excessive delay between a $\mathrm{CO}_{2}$ emission impulse and warming, 
we construct two further artefact models, built on the DICE-Joos-Geoffroy model used to represent the CMIP5 models in Figure 1. These two models exhibit the same long-run temperature response to a $\mathrm{CO}_{2}$ emission impulse as DICE-Joos-Geoffroy, but reach that longrun response at very different speeds; far too slowly in comparison with the climate science models, more in line with the IAMs. The reason we construct these two further models is that, even with the same equilibrium climate sensitivity, the different climate models compared above exhibit not only different short- and medium-run temperature dynamics, they also exhibit different long-run temperature responses (as is clear from Figure 1). The new 'Delay 56' model is so called, because it exhibits a delay between the $\mathrm{CO}_{2}$ emission impulse and peak warming that is five times longer than DICE-Joos-Geoffroy (56 years, rather than 11.2 years). The 'Delay 112 ' model exhibits a corresponding warming delay that is ten times longer. Online Appendix B provides further details of these new models.

Table 4 shows that on the welfare-maximising path an excessive delay leads to lower carbon prices throughout. The 2020 carbon price falls from $\$ 27 / \mathrm{tCO}_{2}$ for the short delay (DICE-Joos-Geoffroy) to $\$ 23$ for the 56-year delay and $\$ 18$ for the 112-year delay (compare rows 2-4). These differences grow over the course of the century. By 2100, moving from a 10 -year delay to a 112 -year delay reduces the optimal carbon price by $\$ 75$, or $38 \%$. With lower carbon prices naturally come higher $\mathrm{CO}_{2}$ emissions, but not higher temperatures, since a longer delay means that it takes much longer for the warming effect of these additional emissions to be realised. Table 5 shows that on the $2^{\circ} \mathrm{C}$ cost-minimising path an excessive delay leads to lower carbon prices in 2020 and 2050. The effect is somewhat smaller than on the optimal path, since the temperature constraint binds and leaves less room for manoeuvre. Lower carbon prices again result in higher emissions, but the delay means this does not translate into higher temperatures; on the contrary.

An implication of these results is that the optimal path may be less sensitive to assumptions about the discount rate than previously thought. Table 6 shows this is indeed the case. We ran DICE-Joos-Geoffroy and the Delay 56 and 112 variants under standard DICE assumptions about the social discount rate (a pure rate of time preference of $1.5 \%$ and an elasticity of marginal utility of consumption of 1.45), and assuming the social planner uses lower values ( $\mathrm{PRTP}=0.1 \%$; elasticity of marginal utility of 1$)$. We call the latter 'public' discounting. ${ }^{15}$ The parameter values are the same as in the Stern Review (Stern, 2007). With a representative initial growth rate of global mean consumption per capita of $2.5 \%$, the standard DICE discount rate is $5.1 \%$ while the 'public' discount rate applied to climate policy is $3.5 \%$. Table 6 shows that the increase in the 2020 optimal carbon price

\footnotetext{
${ }^{15}$ We assume private agents keep the standard DICE parameters for investment/consumption decisions, but that the social planner sets carbon prices using the lower rate (van der Ploeg and Rezai, 2019).
} 
brought about by switching from standard to public discounting is $68 \%$ in Delay 112 , but only $50 \%$ in DICE-Joos-Geoffroy with the short delay. In 2100 the increases are $51 \%$ and $38 \%$ respectively.

To isolate how positive carbon cycle feedbacks affect model paths, we now compare DICEFAIR-Geoffroy and DICE-Joos-Geoffroy (rows 1 and 2). DICE-FAIR-Geoffroy includes such feedbacks, while DICE-Joos-Geoffroy does not. These two models are otherwise identical. Introducing the positive carbon cycle feedbacks results in a higher optimal carbon price. In 2020, the optimal carbon price in DICE-FAIR-Geoffroy is $\$ 29.68 / \mathrm{tCO}_{2}, \$ 2.70$ above the optimal carbon price in DICE-Joos-Geoffroy. Hence the effect is not quantitatively large in the short run. However, it is in the nature of the carbon cycle feedbacks that they have a larger effect, the higher is cumulative absorbed carbon, and temperature, so we see the gap between the models' optimal carbon prices widening steadily until by 2100 it is $\$ 83 / \mathrm{tCO}_{2}$. Higher optimal carbon prices result in lower emissions in DICE-FAIR-Geoffroy and this in turn results in lower 21st-century warming. ${ }^{16}$ Reduced $\mathrm{CO}_{2}$ uptake by carbon sinks reduces the cumulative emissions budget for limiting warming to $2^{\circ} \mathrm{C}$ in DICE-FAIR-Geoffroy, so the $2^{\circ} \mathrm{C}$ cost-minimising carbon price is also higher, resulting in lower emissions and, at least in this century, lower temperatures.

We complete this section with further analysis of two issues. Firstly, Tables 4 and 5 show that DICE 2016 yields higher carbon prices than the benchmark climate science model, DICE-FAIR-Geoffroy (compare rows 1 and 5), particularly on a $2{ }^{\circ} \mathrm{C}$ cost-minimising path. This leads to lower emissions in DICE 2016, yet temperatures end up being higher. Online Appendix $\mathrm{C}$ provides some further analysis of what is behind the difference between standard DICE 2016 and DICE-FAIR-Geoffroy. Three factors are at play, namely differences in (a) temperature dynamics, (b) removal of atmospheric $\mathrm{CO}_{2}$ (under constant background atmospheric $\mathrm{CO}_{2}$ ) and (c) assumptions about positive carbon cycle feedbacks. In online Appendix C, we apportion the difference between (a)-(c) and find that the main driver of different temperatures is (a) the tendency of DICE 2016 to heat up too much in the long run.

Secondly, previous work with DICE 2016 found it is infeasible to limit warming to $2^{\circ} \mathrm{C}$ (Nordhaus, 2017). ${ }^{17}$ Our analysis suggests this is not the case if (a) an appropriate assumption is made about contributions to radiative forcing beyond energy/industrial $\mathrm{CO}_{2}$ and (b) the climate system is appropriately responsive to $\mathrm{CO}_{2}$ emissions. In our $2^{\circ} \mathrm{C}$ cost-minimising runs, we substitute standard DICE 2016 exogenous emissions of $\mathrm{CO}_{2}$ from land-use change

\footnotetext{
${ }^{16}$ Warming is higher in DICE-FAIR-Geoffroy in the longer run, due to the carbon cycle feedbacks' continuing effect. The crossing point is 2200 (not shown). In steady state, optimal warming in DICE-FAIR-Geoffroy is exactly $3^{\circ} \mathrm{C}$, while in DICE-Joos-Geoffroy it peaks at about $2.83^{\circ} \mathrm{C}$.

${ }^{17}$ Under the constraint of no negative emissions technology in the first several decades.
} 


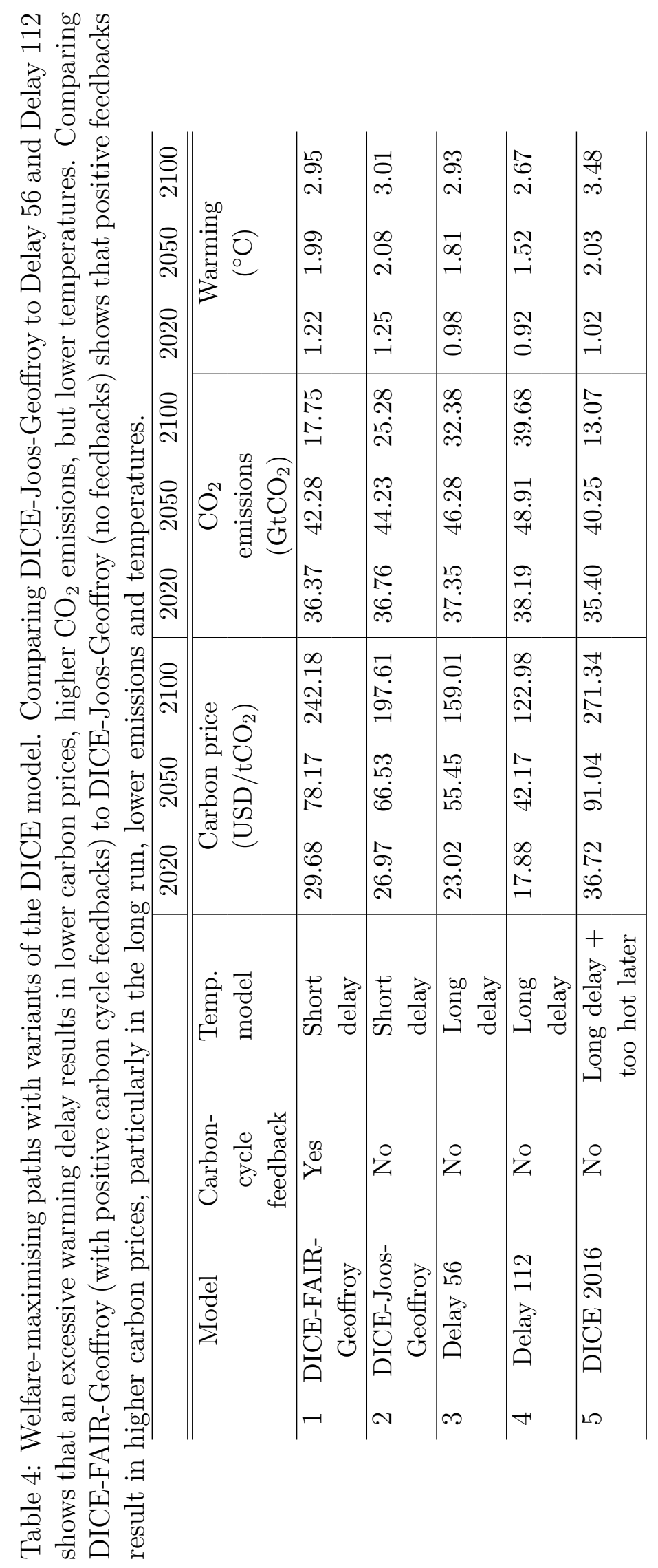




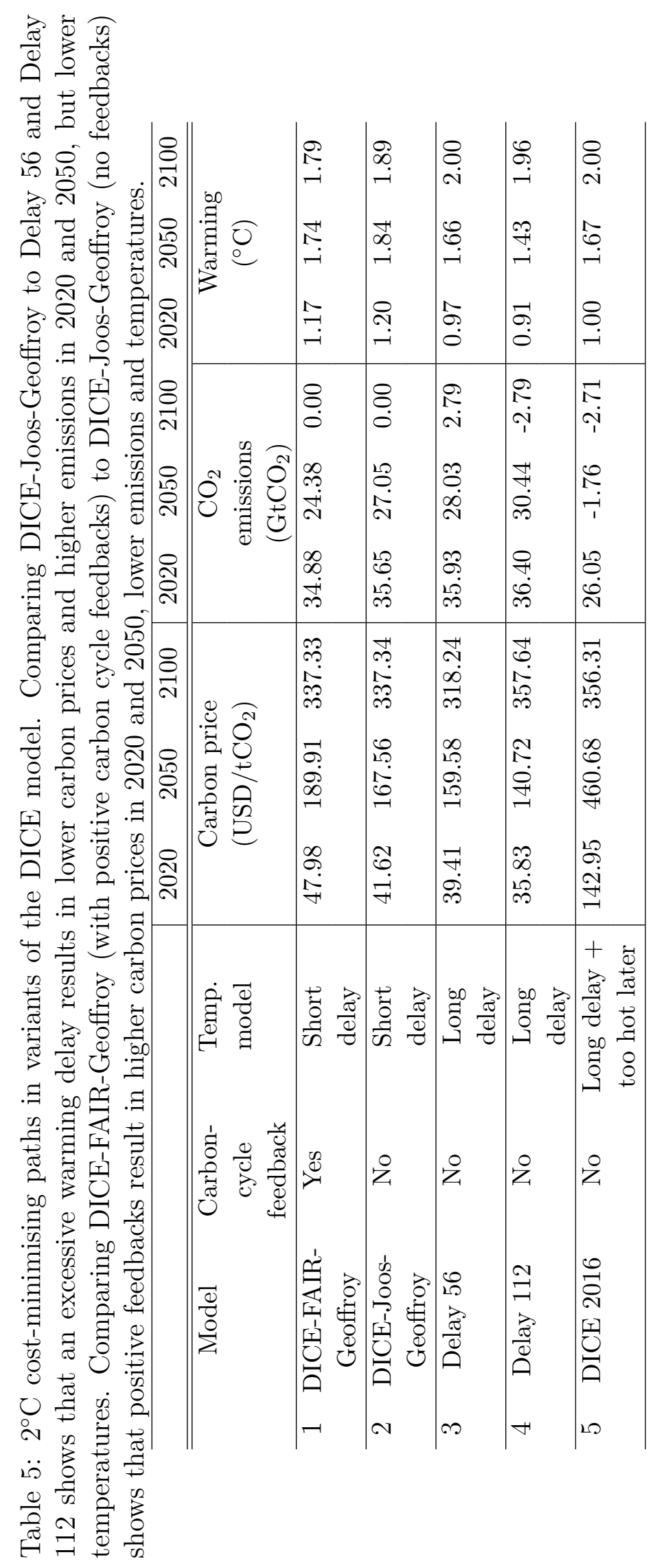




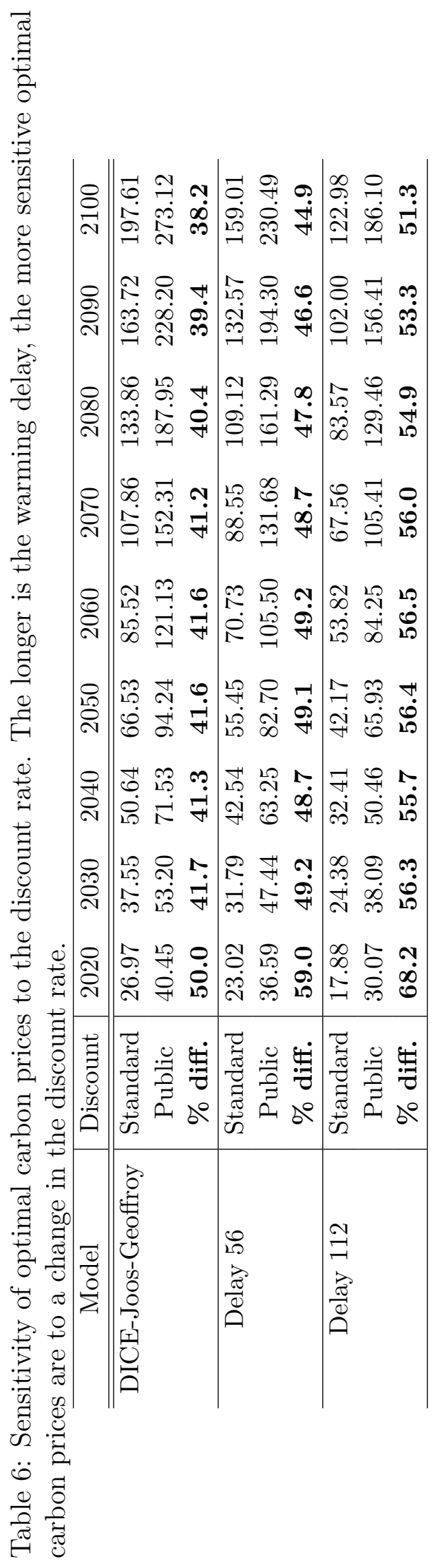


and forestry with corresponding emissions from the IPCC's RCP2.6 scenario ${ }^{18}$, which are lower and more consistent with limiting warming to $2^{\circ} \mathrm{C}$. We do the same for exogenous radiative forcing from other greenhouse gases and atmospheric agents. This explains why we find it is feasible to limit warming to $2^{\circ} \mathrm{C}$ in DICE 2016. However, Figure 5 and Table 5 show that, while it is feasible in DICE 2016, it is still very expensive. It is much less expensive in DICE-FAIR-Geoffroy, due to its more immediate and ultimately lower temperature impulse response to $\mathrm{CO}_{2}$ emissions. Online Appendix $\mathrm{C}$ provides some further analysis of this issue too.

\section{Conclusions and discussion}

We have investigated atmospheric carbon and temperature dynamics in climate models from both climate science and economics. Closely following experimental protocols developed in climate science, we have used reduced-form impulse response functions built to emulate the behaviour of an ensemble of highly non-linear and large-scale Earth System models, and we have compared these with a representative sample of IAMs from the economic literature. We have not been concerned with fitting our reduced-form models to historical data. This would have been a different exercise and the resulting model would be of limited relevance for the analysis of climate policy today. A model calibrated on historical conditions and designed to reproduce the behaviour of past climates is not a reliable model of the future climate. One important reason why is that positive feedbacks in the uptake of atmospheric carbon, studied in some depth in this paper, kick in more strongly when cumulative carbon uptake and temperature are already high (e.g. Millar et al., 2017). This partly explains why climate scientists tend to use the dynamic behaviour of Earth System models in simulation experiments in contemporary and future climatic conditions as their benchmark when building reduced-form models, not past, observed changes in atmospheric carbon and temperature. ${ }^{19}$

There is wide variation in how IAMs simulate the evolution of atmospheric carbon and temperature, but almost all of them are unified in one feature: they show too sluggish a temperature response to an impulse change in $\mathrm{CO}_{2}$ emissions compared with the climate science models. This sluggish temperature response in the IAMs is primarily due to too much temperature inertia in response to elevated atmospheric $\mathrm{CO}_{2}$, rather than $\mathrm{CO}_{2}$ decaying too quickly (on the contrary, in most IAMs it decays too slowly). Besides the sluggish

\footnotetext{
${ }^{18}$ Specifically when combined with the SSP1 socio-economic scenario; see Moss et al. (2010).

${ }^{19}$ That being said, Millar et al. (2017) show that the FAIR model, with its flexible representation of positive carbon cycle feedbacks, closely tracks observed global mean temperature when run with estimated historical greenhouse gas emissions. In addition, Montamat and Stock (2020) provide supporting evidence of the fast temperature impulse response to $\mathrm{CO}_{2}$ emissions, taking an econometric approach to observational data.
} 
temperature response to $\mathrm{CO}_{2}$ emissions, we have also scrutinised the treatment of carbon sinks in the models. In climate science models, carbon sinks weaken due to positive carbon cycle feedbacks. Most IAMs do not demonstrate this property, however.

These discrepancies can cause IAMs to yield misleading policy implications. Controlling for the specification of the economy and welfare using the DICE 2016 economic module, we have found IAMs' climate modules deliver carbon prices, emissions and temperature paths that vary widely and that differ from the benchmark model in climate science. We explored both welfare-maximising carbon prices and carbon prices that ensure a $2^{\circ} \mathrm{C}$ temperature target is achieved at minimum discounted abatement cost. Some models deliver carbon prices that are higher than the benchmark model, some lower. Further exploring the causes of these differences, we found that a sluggish temperature response to $\mathrm{CO}_{2}$ emissions excessive delay - leads to carbon prices that are too low and that are too sensitive to the choice of discount rate, since the costs of global warming are erroneously placed too far in the future. We also found that failing to account for positive carbon cycle feedbacks leads to carbon prices that are too low, especially when atmospheric $\mathrm{CO}_{2}$ is high. But even if the temperature response to $\mathrm{CO}_{2}$ emissions is too slow and positive carbon cycle feedbacks are omitted, carbon prices can still be too high in IAMs, as appears to be the case in DICE 2016, which has too high a long-run temperature response.

Therefore climate dynamics matter for economic policy prescriptions. We do not claim they matter more than other causes célèbres in climate economics like the social discount rate or the damage function, but matter they do. Moreover, in contrast to these other issues, on which research is ongoing but seemingly far from a definitive conclusion, the discrepancies we have identified between economic models and climate science models can easily be fixed.

We can readily identify two options. The first is to recalibrate or replace the climate modules in IAMs. Models of the carbon cycle need to incorporate positive feedback effects, as FAIR does (Millar et al., 2017). Models of temperature dynamics need to either be replaced or recalibrated, so that they can reproduce the fast temperature response of Earth System models to $\mathrm{CO}_{2}$ emissions, as the model of Geoffroy et al. (2013) does. Recall the Geoffroy et al. model is structurally identical to the DICE climate module, so DICE would simply need to be recalibrated. Online Appendix D provides GAMS code to implement the FAIR-Geoffroy climate in DICE. Hänsel et al. (2020) is a very recent example of running DICE with the FAIR-Geoffroy climate. Other simple models in climate science may do the same job. None of these changes requires significant complication of existing IAMs.

The second option is simply to specify temperature as a linear function of cumulative $\mathrm{CO}_{2}$ emissions (Collins et al., 2013). This is an indirect solution to the problem, because it turns out that the step temperature impulse response function and positive carbon cycle 
feedbacks combine to produce this linear response in terms of cumulative $\mathrm{CO}_{2}$ emissions (Dietz and Venmans, 2019). ${ }^{20}$ Appendix E demonstrates this: the CMIP5 models exhibit an approximately linear warming response to cumulative emissions under various IPCC emissions scenarios. The IAMs tend not to. The CMIP5 ensemble gives multi-model mean temperature at time $t$ as $1^{\circ} \mathrm{C}$ plus $1.7^{\circ} \mathrm{C}$ per trillion tons of cumulative emissions (TtC) from 2020 onwards. Warming from non- $\mathrm{CO}_{2}$ greenhouse gases needs to be added on top. The slope coefficient of $1.7^{\circ} \mathrm{C} / \mathrm{TtC}$ is known as the Transient Climate Response to Cumulative Carbon Emissions (TCRE). ${ }^{21}$ As well as being consistent with the climate science models for sound physical reasons, the linear warming-cumulative $\mathrm{CO}_{2}$ relationship is also very simple and reduces the number of state variables needed to represent the climate system, which is advantageous for analytical models in particular.

All the models we have discussed are deterministic. But since the CMIP5 ensemble contains a lot of variation, and there are climate system uncertainties beyond what the CMIP5 ensemble captures, it may be useful to derive stochastic reduced-form models of the atmospheric carbon stock and temperature dynamics (e.g. van der Ploeg, 2018; Aengenheyster et al., 2018). One could then find, for example, the carbon budget compatible with a certain tolerance of overshooting the $2^{\circ} \mathrm{C}$ target (e.g. 1/3). Miftakhova et al. (2020) use a general emulation method for constructing low-dimensional stochastic approximations of complex climate models. Their best model gives a simple stochastic linear exponential lag model between temperature and cumulative $\mathrm{CO}_{2}$ emissions. Alternatively, one could follow Pretis (2020), who builds on Kaufmann et al. (2011) and shows that energy-balance models of temperatures, ocean heat content and radiative forcing including greenhouse gases are equivalent to an econometric co-integrated system and can be estimated in discrete time. He shows that accounting for structural breaks from volcanic eruptions indicates large parameter uncertainties and that ignoring these breaks can lead to misleading policy implications due to model mis-specification. The model can then be used to quantify uncertainties in the dynamics of the atmospheric carbon stock and temperature.

\footnotetext{
${ }^{20}$ Some recent studies that have used this simple relationship to derive economically optimal climate policies are Allen (2016), Brock and Xepapadeas (2017), van der Ploeg (2018), Manoussi et al. (2018) and Dietz and Venmans (2019).

${ }^{21}$ The simple formula whereby warming $=$ TCRE $\mathrm{x}$ cumulative emissions implies a temperature response function to a $\mathrm{CO}_{2}$ emission impulse that is approximated by a step function with amplitude equal to the TCRE. The temperature response function that best fits the CMIP5 ensemble in the experiment reported in Figure 1 has a mean amplitude of $1.72^{\circ} \mathrm{C} / \mathrm{TtC}$. This is for an equilibrium climate sensitivity of $3.1^{\circ} \mathrm{C}$. FAIR has a mean amplitude of $1.77^{\circ} \mathrm{C} / \mathrm{TtC}$ under 2015 conditions. Equilibrium climate sensitivity is the largest source of uncertainty about the TCRE. Matthews et al. (2009) found a 5-95\% probability range of 1.0-2. $1^{\circ} \mathrm{C} / \mathrm{TtC}$, Allen et al. (2009) found $1.4-2.5^{\circ} \mathrm{C} / \mathrm{TtC}$ and Gillett et al. (2013) found $0.7-2.0^{\circ} \mathrm{C} / \mathrm{TtC}$ based on the CMIP5 ensemble. Based on this and other evidence, IPCC adopted a 'likely' range of $1.0-2.1^{\circ} \mathrm{C} / \mathrm{TtC}$ (Collins et al., 2013). Recently Nijsse et al. (2020) have suggested $1.3-2.1^{\circ} \mathrm{C} / \mathrm{TtC}$ based on the emerging results from CMIP6, with a most likely value of $1.68^{\circ} \mathrm{C} / \mathrm{TtC}$.
} 
IAMs tend to abstract from statistical and model uncertainty. We know that these uncertainties (especially the skewed distribution of the climate sensitivity and the effect of stochastic tipping points) can have large positive impacts on the optimal carbon price. To model such uncertainties properly, one cannot use the simple linear relationship between temperature and cumulative emissions, as this does not appear to hold at high temperatures (MacDougall, 2016), whilst in stochastic analysis one is interested in extreme outcomes even if they are quite unlikely. Future research should therefore be directed at finding reliable stochastic representations of the inherent statistical and modelling uncertainties in the CMIP5 ensemble and other ensembles. Only by accounting for the various forms of uncertainty will it be possible to find climate policies that are robust and prudent. 


\section{References}

Aengenheyster, Matthias, Qing Yi Feng, Frederick Van Der Ploeg, and Henk A Dijkstra, "The point of no return for climate action," Earth System Dynamics, 2018, 9 $(3)$.

Allen, Myles R, "Drivers of peak warming in a consumption-maximizing world," Nature Climate Change, 2016, 6, 684-686.

_, David J Frame, Chris Huntingford, Chris D Jones, Jason A Lowe, Malte Meinshausen, and Nicolai Meinshausen, "Warming caused by cumulative carbon emissions towards the trillionth tonne," Nature, 2009, 458 (7242), 1163-1166.

Arrow, Kenneth, Maureen Cropper, Christian Gollier, Ben Groom, Geoffrey Heal, Richard Newell, William Nordhaus, Robert Pindyck, William Pizer, Paul Portney et al., "Determining benefits and costs for future generations," Science, 2013, 341 (6144), 349-350.

Brock, William and Anastasios Xepapadeas, "Climate change policy under polar amplification," European Economic Review, 2017, 99, 93-112.

Calel, Raphael and David A Stainforth, "On the physics of three integrated assessment models," Bulletin of the American Meteorological Society, 2017, 98 (6), 1199-1216.

Clarke, L., K. Jiang, K. Akimoto et al., "Asessing transformation pathways," in O. Edenhofer, R. Pichs-Madruga, Y. Sokona et al., eds., Climate Change 2014: Mitigation of Climate Change. Contribution of Working Group III to the Fifth Assessment Report of the Intergovernmental Panel on Climate Change, Cambridge, UK and New York, NY, USA: Cambridge University Press, 2014.

Collins, M., R. Knutti, J. Arblaster, J.-L. Dufresne, T. Fichefet, P. Friedlingstein, X. Gao, W.J. Gutowski, T. Johns, G. Krinner, M. Shongwe, C. Tebaldi, Weaver A.J., and M. Wehner, "Long-term climate change: projections, commitments and irreversibility," in T.F. Stocker, C. Qin, G.-K. Plattner, M. Tignor, S.K. Allen, J. Boschung, A. Nauels, Y. Xia, V. Bex, and P.M. Midgeley, eds., Climate Change 2013: The Physical Science Basis. Contribution of Working Group I to the Fifth Assessment Report of the Intergovernmental Panel on Climate Change, Cambridge, UK and New York, NY, USA: Cambridge University Press, 2013. 
Dietz, Simon and Frank Venmans, "Cumulative carbon emissions and economic policy: in search of general principles," Journal of Environmental Economics and Management, 2019, 96, 108-129.

Friedlingstein, Pierre, Peter Cox, Richard Betts, Laurent Bopp, Werner von Bloh, Victor Brovkin, Patricia Cadule, Scott Doney, Michael Eby, Inez Fung et al., "Climate-carbon cycle feedback analysis: results from the C4MIP model intercomparison," Journal of Climate, 2006, 19 (14), 3337-3353.

Geoffroy, Olivier, David Saint-Martin, Dirk JL Olivié, Aurore Voldoire, Gilles Bellon, and Sophie Tytéca, "Transient climate response in a two-layer energy-balance model. Part I: Analytical solution and parameter calibration using CMIP5 AOGCM experiments," Journal of Climate, 2013, 26 (6), 1841-1857.

Gerlagh, Reyer and Matti Liski, "Consistent climate policies," Journal of the European Economic Association, 2018, 16 (1), 1-44.

Gillett, Nathan P, Vivek K Arora, Damon Matthews, and Myles R Allen, "Constraining the ratio of global warming to cumulative CO2 emissions using CMIP5 simulations," Journal of Climate, 2013, 26 (18), 6844-6858.

Gollier, Christian, Pricing the Planet's Future: The Economics of Discounting in an Uncertain World, Princeton University Press, 2012.

Golosov, Mikhail, John Hassler, Per Krusell, and Aleh Tsyvinski, "Optimal taxes on fossil fuel in general equilibrium," Econometrica, 2014, 82 (1), 41-88.

Hänsel, Martin C, Moritz A Drupp, Daniel JA Johansson, Frikk Nesje, Christian Azar, Mark C Freeman, Ben Groom, and Thomas Sterner, "Climate economics support for the UN climate targets," Nature Climate Change, 2020, 10 (8), 781-789.

Hooss, Georg, Reinhard Voss, Klaus Hasselmann, Ernst Maier-Reimer, and Fortunat Joos, "A nonlinear impulse response model of the coupled carbon cycle-climate system (NICCS)," Climate Dynamics, 2001, 18 (3-4), 189-202.

Hope, Chris, "Critical issues for the calculation of the social cost of CO2: why the estimates from PAGE09 are higher than those from PAGE2002," Climatic Change, 2013, 117 (3), $531-543$.

Interagency Working Group on Social Cost of Carbon, "Technical update on the social cost of carbon for regulatory impact analysis under executive order 12866," Technical 
Report, Interagency Working Group on Social Cost of Carbon, United States Government 2013.

IPCC, Climate Change 2013: The Physical Science Basis. Contribution of Working Group I to the Fifth Assessment Report of the Intergovernmental Panel on Climate Change, Cambridge, United Kingdom and New York, NY, USA: Cambridge University Press, 2013.

Joos, Fortunat, Raphael Roth, JS Fuglestvedt, GP Peters, IG Enting, W von Bloh, V Brovkin, EJ Burke, M Eby, NR Edwards et al., "Carbon dioxide and climate impulse response functions for the computation of greenhouse gas metrics: a multi-model analysis," Atmospheric Chemistry and Physics, 2013, 13 (5), 2793-2825.

Kaufmann, Robert K, Heikki Kauppi, Michael L Mann, and James H Stock, "Reconciling anthropogenic climate change with observed temperature 1998-2008," Proceedings of the National Academy of Sciences, 2011, 108 (29), 11790-11793.

Lemoine, Derek and Ivan Rudik, "Steering the climate system: using inertia to lower

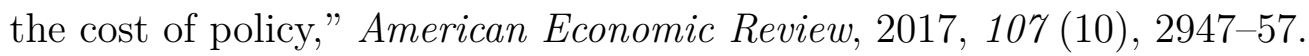

Lenton, Timothy M, Hermann Held, Elmar Kriegler, Jim W Hall, Wolfgang Lucht, Stefan Rahmstorf, and Hans Joachim Schellnhuber, "Tipping elements in the Earth's climate system," Proceedings of the National Academy of Sciences, 2008, 105 (6), 1786-1793.

MacDougall, Andrew H, "The transient response to cumulative CO2 emissions: a review," Current Climate Change Reports, 2016, 2 (1), 39-47.

Maier-Reimer, Ernst and Klaus Hasselmann, "Transport and storage of $\mathrm{CO}_{2}$ in the ocean: an inorganic ocean-circulation carbon cycle model," Climate dynamics, 1987, 2(2), $63-90$.

Manoussi, Vassiliki, Anastasios Xepapadeas, and Johannes Emmerling, "Climate engineering under deep uncertainty," Journal of Economic Dynamics and Control, 2018, $94,207-224$.

Mattauch, Linus, H Damon Matthews, Richard Millar, Armon Rezai, Susan Solomon, and Frank Venmans, "Steering the climate system: Comment," American Economic Review, 2020, 110 (4), 1231-1237.

Matthews, H Damon, Nathan P Gillett, Peter A Stott, and Kirsten Zickfeld, "The proportionality of global warming to cumulative carbon emissions," Nature, 2009, 459 (7248), 829-832. 
Miftakhova, Alena, Kenneth L Judd, Thomas S Lontzek, and Karl Schmedders, "Statistical approximation of high-dimensional climate models," Journal of Econometrics, 2020, 214 (1), 67-80.

Millar, Richard J, Zebedee R Nicholls, Pierre Friedlingstein, and Myles R Allen, "A modified impulse-response representation of the global near-surface air temperature and atmospheric concentration response to carbon dioxide emissions," Atmospheric Chemistry and Physics, 2017, 17 (11), 7213-7228.

Montamat, Giselle and James H Stock, "Quasi-experimental estimates of the transient climate response using observational data," Climatic Change, 2020, pp. 1-11.

Moss, Richard H, Jae A Edmonds, Kathy A Hibbard, Martin R Manning, Steven K Rose, Detlef P Van Vuuren, Timothy R Carter, Seita Emori, Mikiko Kainuma, Tom Kram et al., "The next generation of scenarios for climate change research and assessment," Nature, 2010, 463 (7282), 747-756.

National Academies of Sciences, Engineering, and Medicine, Valuing Climate Damages: Updating Estimation of the Social Cost of Carbon Dioxide, National Academies Press, 2017.

Nijsse, Femke JMM, Peter M Cox, and Mark S Williamson, "Emergent constraints on transient climate response (TCR) and equilibrium climate sensitivity (ECS) from historical warming in CMIP5 and CMIP6 models," Earth System Dynamics, 2020, 11 (3), $737-750$.

Nordhaus, William D, "A review of the "Stern Review on the Economics of Climate Change"," Journal of Economic Literature, 2007, 45, 686-702.

_ , "Estimates of the social cost of carbon: concepts and results from the DICE-2013R model and alternative approaches," Journal of the Association of Environmental and Resource Economists, 2014, 1 (1/2), 273-312.

_- "Revisiting the social cost of carbon," Proceedings of the National Academy of Sciences, 2017, 114 (7), 1518-1523.

Pretis, Felix, "Econometric modelling of climate systems: The equivalence of energy balance models and cointegrated vector autoregressions," Journal of Econometrics, 2020, 214 (1), 256-273. 
Quéré, Corinne Le, Robbie M. Andrew, Pierre Friedlingstein, Stephen Sitch, Judith Hauck, Julia Pongratz, Penelope A. Pickers, Jan Ivar Korsbakken, Glen P. Peters, Josep G. Canadell, Almut Arneth, Vivek K. Arora, Leticia Barbero, Ana Bastos, Laurent Bopp, Frédéric Chevallier, Louise P. Chini, Philippe Ciais, Scott C. Doney, Thanos Gkritzalis, Daniel S. Goll, Ian Harris, Vanessa Haverd, Forrest M. Hoffman, Mario Hoppema, Richard A. Houghton, George Hurtt, Tatiana Ilyina, Atul K. Jain, Truls Johannesen, Chris D. Jones, Etsushi Kato, Ralph F. Keeling, Kees Klein Goldewijk, Peter Landschützer, Nathalie Lefèvre, Sebastian Lienert, Zhu Liu, Danica Lombardozzi, Nicolas Metzl, David R. Munro, Julia E. M. S. Nabel, Shin ichiro Nakaoka, Craig Neill, Are Olsen, Tsueno Ono, Prabir Patra, Anna Peregon, Wouter Peters, Philippe Peylin, Benjamin Pfeil, Denis Pierrot, Benjamin Poulter, Gregor Rehder, Laure Resplandy, Eddy Robertson, Matthias Rocher, Christian Rödenbeck, Ute Schuster, Jörg Schwinger, Roland Séférian, Ingunn Skjelvan, Tobias Steinhoff, Adrienne Sutton, Pieter P. Tans, Hanqin Tian, Bronte Tilbrook, Francesco N. Tubiello, Ingrid T. van der Laan-Luijkx, Guido R. van der Werf, Nicolas Viovy, Anthony P. Walker, Andrew J. Wiltshire, Rebecca Wright, Sönke Zaehle, and Bo Zheng, "Global Carbon Budget 2018," Earth System Science Data, 2018.

Revelle, Roger and Hans E Suess, "Carbon dioxide exchange between atmosphere and ocean and the question of an increase of atmospheric $\mathrm{CO} 2$ during the past decades," Tellus, 1957, 9 (1), 18-27.

Ricke, Katharine L and Ken Caldeira, "Maximum warming occurs about one decade after a carbon dioxide emission," Environmental Research Letters, 2014, 9 (12), 124002.

Rose, Steven K, Delavane B Diaz, and Geoffrey J Blanford, "Understanding the social cost of carbon: a model diagnostic and inter-comparison study," Climate Change Economics, 2017, 8 (02), 1750009.

Stern, N., The Economics of Climate Change: the Stern Review, Cambridge University Press, 2007.

van der Ploeg, Frederick, "The safe carbon budget," Climatic Change, 2018, 147 (1-2), $47-59$.

- and Armon Rezai, "The agnostic's response to climate deniers: Price carbon!," European Economic Review, 2019, 111, 70-84. 
van Vuuren, Detlef P, Jason Lowe, Elke Stehfest, Laila Gohar, Andries F Hof, Chris Hope, Rachel Warren, Malte Meinshausen, and Gian-Kasper Plattner, "How well do integrated assessment models simulate climate change?," Climatic Change, 2011, 104 (2), 255-285.

Waldhoff, Stephanie T, David Anthoff, Steven Rose, and Richard SJ Tol, "The marginal damage costs of different greenhouse gases:aAn application of FUND," Economics: The Open-Access, Open-Assessment E-Journal, 2014, 8 (1). 